\title{
Dynamic of Friction Coupling Independently Rotating Wheels for High Speed
}

\author{
Yan Shi, Miao Li, Weihua Ma, and Kang Chen \\ Traction Power State Key Laboratory, Southwest JiaoTong University, Chengdu, China \\ Correspondence should be addressed to Weihua Ma; mwh@swjtu.cn
}

Received 24 May 2017; Revised 18 August 2017; Accepted 13 September 2017; Published 12 October 2017

Academic Editor: Chao Tao

Copyright (C) 2017 Yan Shi et al. This is an open access article distributed under the Creative Commons Attribution License, which permits unrestricted use, distribution, and reproduction in any medium, provided the original work is properly cited.

\begin{abstract}
A new lateral coupling structure with independently rotating wheels (IRW) is proposed, and longitudinal creepage is obtained by replacing the gear pair with the friction pair to synchronize the rotation speed of left and right wheels. The auxiliary wheelset made up of two friction wheels can be placed either under the primary suspension or on the frame. Vehicles dynamics models with three different kinds of bogies are developed, including friction coupling bogie with independently rotating wheels (FCIRW-bogie), bogie with independently rotating wheels (IRW-bogie), and bogie with rigid wheelsets, and their guiding and resetting capability when negotiating large-radius curves are compared and analyzed. Results show that FCIRW has the advantages of both IRW and rigid wheelset. On the straight track, FCIRW has sufficient wheel-rail longitudinal creep force to assist the reset; its critical speed is much higher than that of the rigid wheelset. On the curved track, the whole vehicle wear power of FCIRW-bogie vehicle is about $2 / 3$ of the rigid axle level.
\end{abstract}

\section{Introduction}

With the development of low-floor tram technology, low floor is more frequently applied and $100 \%$ low-floor vehicles have been widely used. To achieve this, the conventional space for axles must be spared, which is exactly why wheelset-axledecoupled IRW bogies are extensively applied in low-floor light rail vehicles. IRW wheelset refers to a pair of left and right wheels which can keep parallel to each other and rotate freely around their axles, respectively, as there is no rigid connection between the wheels. In a steady state, IRW has no longitudinal creepage [1]; accordingly there is no longitudinal creep force and the gyroscopic moment generated solely by gyroscopic creep is also very small. Without self-excited vibration source, the independent wheelset does not vibrate in the form of hunting motion, so stable vehicle system running on the straight track will not destabilize along with the increase of the running speed. More importantly, the lateral contact force and wear between the wheel and the rail are much smaller than those of the wheelset with rigid connection. The use of IRW can significantly reduce the wear and noise between the wheel and rail, which is quite important for the maintenance of both the vehicle and track as well as the protection of the environment. At the same time, IRW bogie can shorten the wheelbase and reduce the size and weight of the bogie, both of which are conducive to the design of bogie for high-speed running on existing curved track as well as bogie on light truck. NGT, the next-generation high-speed train, developed by DLR, the German Aerospace Center, is expected to realize the idea of double-decker high-speed trains by using IRW bogies, which will greatly improve the economic efficiency [2]. From the perspective of economic efficiency, high-speed trains with double-decker design can take more passengers within the same section height and transport more passengers with the same unit energy consumption. One way to increase the section height is to utilize the space for axle, which can only be realized by adopting IRW bogies.

Without gyroscopic creep moment, IRW wheelset does not retain resetting and automatic guiding capability. Therefore, since the 1930s, various kinds of IRW bogies have been developed to solve the guiding problem [3], and diversified development modes have been formed [4]. Among them, lateral coupling IRW bogie and longitudinal coupling IRW bogie are widely used in the low-floor light rail vehicle because of their simple guide mechanism and relatively 


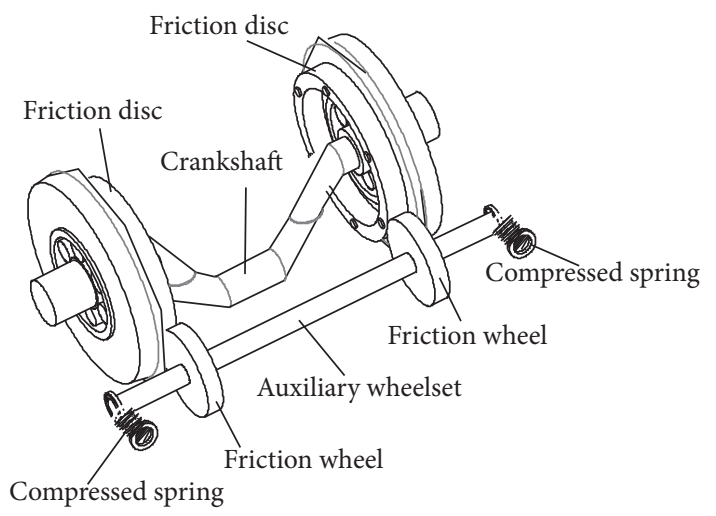

(a) FCIRW

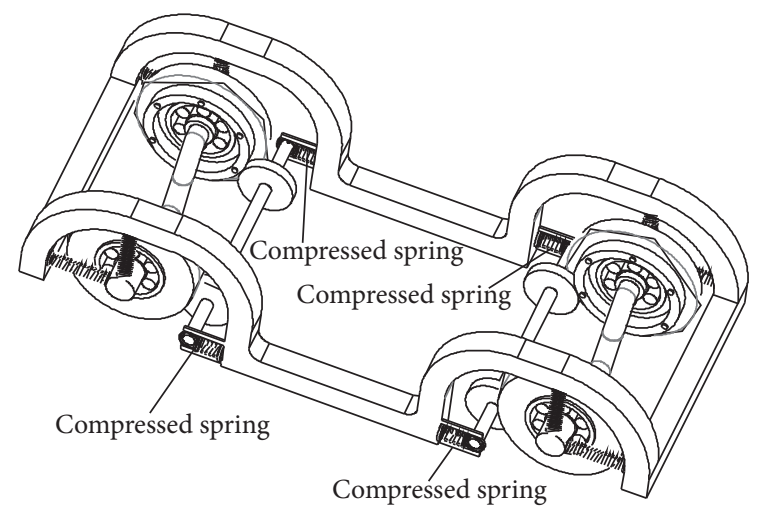

(b) FCIRW-bogie

FIgURE 1: Structure of FCIRW.

low cost. For longitudinal coupling IRW bogie, the left and right wheels are completely independent of each other while rotating, without coupling devices in between; the two wheels on the same side of the bogie synchronize their speed [5] through a kind of mechanism. For example, the Combino power bogie developed by Siemens of Germany uses mechanical axle to longitudinally couple the front and rear wheels on the same side so that they have the same rotation angular velocity [6]. By longitudinal coupling, IRW bogie has regained its guiding capability. Another way is to recouple the left and right wheels through the axle bridge mechanism [7], forming the lateral coupling IRW bogie.

In this paper, the lateral coupling IRW mechanism is improved and vehicle dynamics models with FCIRW-bogie are developed. Analyses are made between the performances of vehicles with FCIRW-bogie, IRW-bogie, and bogie with rigid wheelset running on large-radius curves at high speed, and comparatively satisfactory high-speed dynamics performance of FCIRW-bogie is achieved.

\section{FCIRW-Bogie}

2.1. Structure. The lateral coupling IRW bogie, in effect, recouples the decoupled left and right wheels and introduces rigidness and damping between the independently rotatable wheels, allowing IRW wheelset to achieve the same guiding capability as conventional rigid wheelset.

For friction-pair transmission, the contact surface of the two friction wheels can skid, which indicates that the frictionpair transmission has the function of overload protection as the belt transmission. As is shown in Figure 1, the gear pair is replaced by the friction pair. The transferring moment of the friction pair is less than that of the gear pair, so that the lightweight material such as aluminum can be chosen in order to reduce the unsprung mass. The positive pressure between the friction wheel and the friction disk is provided by the compressed spring. One end of the compressed spring is on the auxiliary wheelset, and the other end is on the frame. If the friction between the friction wheel and the friction disk is too small, there will be no coupling effect between the left and the right wheels; if the friction is too large, the operation resistance will be large. Therefore, the principle of determining the positive pressure is that there is coupling effect between the left and the right wheels.

2.2. The Guiding Mechanism. The poor guiding performance of the IRW is the main reason that restricts its application. Therefore, the guiding mechanism of the independent rotating wheel is the key point for research. A German researcher named Leo has first used a variable electromagnetic coupling between the two wheels in the wheelset to study the "creepcontrolled wheelset." The basic idea was to shift some of the creep from the wheel contact area to the coupling $[8,9]$, thereby diminishing the longitudinal creep. Comprehensive testing was undertaken on a roller rig, with speeds of up to $500 \mathrm{~km} / \mathrm{h}$. The left and right wheels coupled in a passive mode have been adopted in this article and relevant researches have been carried out.

As shown in Figure 2, FCIRW runs at a uniform speed of $V$ along the straight track, and the wheels rotate around their axles at an angular velocity of $\omega ; y, \psi, \varphi$ are the lateral displacement, yaw angle, and roll angle of the wheelset, respectively; $r_{L}, r_{R}$ are the rolling circle radius of the left and right wheels; $r_{0}$ is the nominal rolling circle radius of the left and right wheels; $r_{0}=V / \omega ; \lambda$ is wheel tread taper. Then, the following equations can be obtained [10]:

$$
\begin{aligned}
& r_{L}=r_{0}+\lambda y, \\
& r_{R}=r_{0}-\lambda y .
\end{aligned}
$$

When the creepage is small, there is a linear relationship between creep force and creepage. In the case of small disturbance on the wheelset, ignoring its spin creep, the creep force between the wheel and rail is calculated by Kalker linear theory [11].

If there is sliding between the friction wheel and the friction disc, and the left and right wheels are not completely decoupled, longitudinal velocity at the contact point is close 


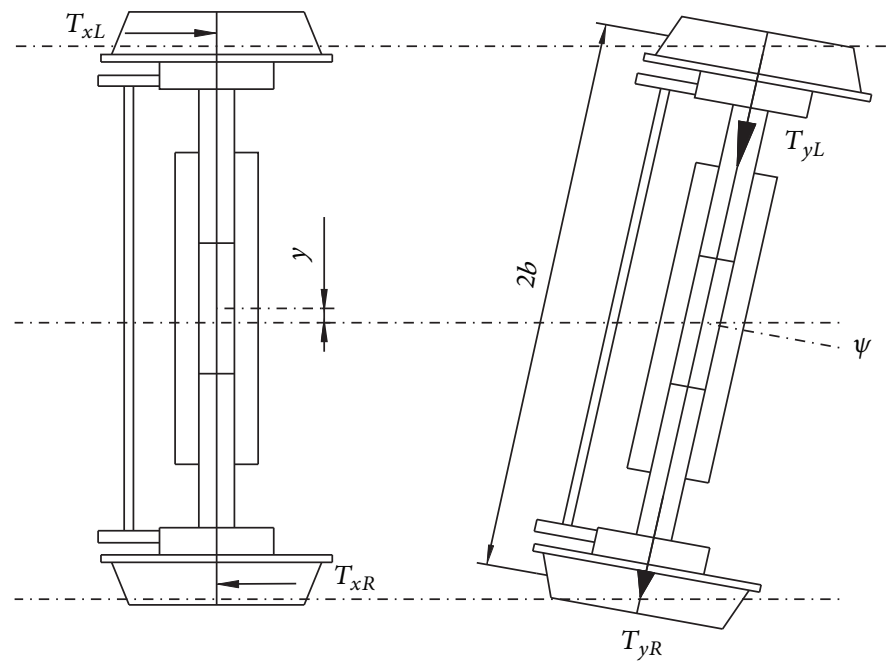

(a) Lateral displacement

(b) Yaw motion

FIGURE 2: Lateral displacement and yaw motion under the acting of creep force.

to the track speed. Longitudinal creepages of the left and right wheels are given by $[12,13]$

$$
\begin{aligned}
& \xi_{x L}=\frac{\left(V-\omega_{L} r_{L}\right)-b \dot{\psi}}{V}, \\
& \xi_{x R}=\frac{\left(V-\omega_{R} r_{R}\right)+b \dot{\psi}}{V} .
\end{aligned}
$$

Longitudinal creep forces of the left and right wheel can be written as

$$
\begin{aligned}
& T_{x L}=-f_{11} \xi_{x L}=f_{11} \frac{b \dot{\psi}-\left(V-\omega_{L} r_{L}\right)}{V}, \\
& T_{x R}=-f_{11} \xi_{x R}=-f_{11} \frac{b \dot{\psi}+\left(V-\omega_{R} r_{R}\right)}{V} .
\end{aligned}
$$

The lateral creepage of the left and right wheels is the same, which is given by

$$
\xi_{y}=\frac{\dot{y}}{V}-\psi
$$

The lateral creep force of the left and right wheels is defined as

$$
T_{y L}=T_{y R}=-f_{22} \xi_{y}=f_{22}\left(\psi-\frac{\dot{y}}{V}\right) .
$$

If the left and right wheels are completely decoupled, the guiding mechanisms of FCIRW and IRW are exactly the same, which can be demonstrated by

$$
\begin{aligned}
& V-\omega_{L} r_{L}=0, \\
& V-\omega_{R} r_{R}=0 .
\end{aligned}
$$

Integrating equations (4), (5), and (8), longitudinal creep moment can be defined as

$$
M_{z}=\left(T_{x R}-T_{x L}\right) \cdot b=-2 f_{11} \frac{b^{2}}{V} \dot{\psi} .
$$

If there is no sliding between the friction wheel and the friction disc and the rotation speed of the left and right wheels are the same, $\omega_{L}=\omega_{R}=\omega$, the guiding mechanisms of FCIRW and rigid wheelset are exactly the same. By integrating equations (1) and (2) into equations (4) and (5), respectively, longitudinal creep forces of the left and right wheel can be put as follows:

$$
\begin{aligned}
& T_{x L}=f_{11}\left(\frac{\lambda y}{r_{o}}+\frac{b \dot{\psi}}{V}\right), \\
& T_{x R}=-f_{11}\left(\frac{\lambda y}{r_{o}}+\frac{b \dot{\psi}}{V}\right) .
\end{aligned}
$$

It can be seen that longitudinal creep forces acting on the left and right wheels are equal in size yet opposite in direction, and thus the longitudinal creep moment is given by

$$
M_{z}=\left(T_{x R}-T_{x L}\right) \cdot b=-2 f_{11}\left(\frac{\lambda b}{r_{o}} y+\frac{b^{2}}{V} \dot{\psi}\right) .
$$

The lateral coupling method does not affect the lateral creep force of IRW.

\section{Dynamics Model}

To determine wheelset performance, the performance of the vehicle as a whole should be considered. In this paper, biaxial bogie is taken as the research object and vehicle dynamics models are developed with the use of SIMPACK, the multibody dynamics software, as shown in Figure 3, including a car body, two biaxial bogies, and eight axle boxes. The vehicle system is regarded as a complex multibody, multi-degree-of-freedom nonlinear vibration system, with each rigid body linked via springs and dampers, without considering the elastic deformation of car body, bogie frame, wheelsets, and other components. 
TABLE 1: Characteristic of bogies and track.

\begin{tabular}{lcc}
\hline Number & Parameter & Value \\
\hline$(1)$ & Mass of the car body & $40000 \mathrm{~kg}$ \\
$(2)$ & Mass of the bogie & $2760 \mathrm{~kg}$ \\
$(3)$ & Mass of the wheelset & $2580 \mathrm{~kg}$ \\
$(4)$ & Length between bogie centers & $12.3 \mathrm{~m}$ \\
$(5)$ & Axle base & $2.3 \mathrm{~m}$ \\
$(6)$ & Nominal wheel radius & $0.5 \mathrm{~m}$ \\
$(7)$ & Primary suspension stiffness & $20 / 5 / 2 \mathrm{MN} / \mathrm{m}$ \\
$(8)$ & $(x / y / z)$ & $5 \mathrm{kN} \cdot \mathrm{s} / \mathrm{m}$ \\
$(9)$ & Primary damper $(x / y / z)$ & $138 / 138 / 473 \mathrm{kN} / \mathrm{m}$ \\
$(10)$ & Secondary suspension & $2 \mathrm{kN} \cdot \mathrm{s} / \mathrm{m}$ \\
$(11)$ & stiffness $(x / y / z)$ & $\mathrm{JM} 3$ \\
$(12)$ & Secondary damper $(x / y / z)$ & $\mathrm{UIC} 60$ \\
$(13)$ & Wheel profile & 1.435 \\
$(14)$ & Rail profile & $1: 40$ \\
\hline
\end{tabular}

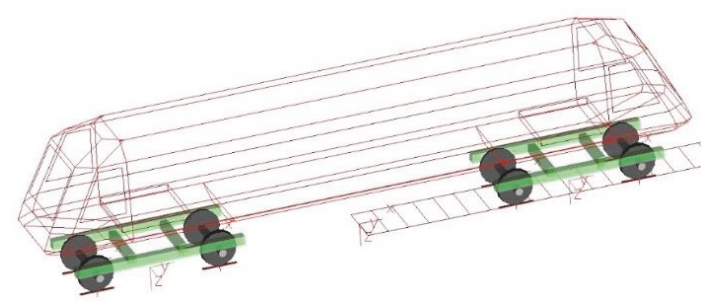

FIgURE 3: Dynamics model of the whole vehicle.

There are three types of vehicles: FCIRW-bogie vehicles, IRW-bogie vehicles, and vehicles with rigid wheelset bogie, depending on the wheelset structure. They have the same suspension parameters and tread, as shown in Table 1. The longitudinal stiffness has a significant effect on the critical speed of the vehicle. In order to compare and analyze the performances when the vehicle passes the curve at a high speed, $20 \mathrm{MN} / \mathrm{m}$ is set as the longitudinal stiffness.

Eight force elements of number 45 are used in FCIRWbogie to provide the friction between the friction wheel and the friction disc. Figure 4 shows its relevant parameters. Dynamics model of FCIRW-bogie is shown in Figure 5(a): the auxiliary wheelset made up of two friction wheels is suspended on the frame.

Figure 5(b) is the model of IRW-bogie, where the auxiliary wheelset, friction discs, and force element number 45 are omitted compared with FCIRW-bogie. Model of bogie with rigid wheelset is shown in Figure 5(c).

\section{Results}

The performance of three bogies is mainly compared and analyzed from the angle of attack, wheel-rail lateral force, and wear power. The relationship between wheel-rail contact

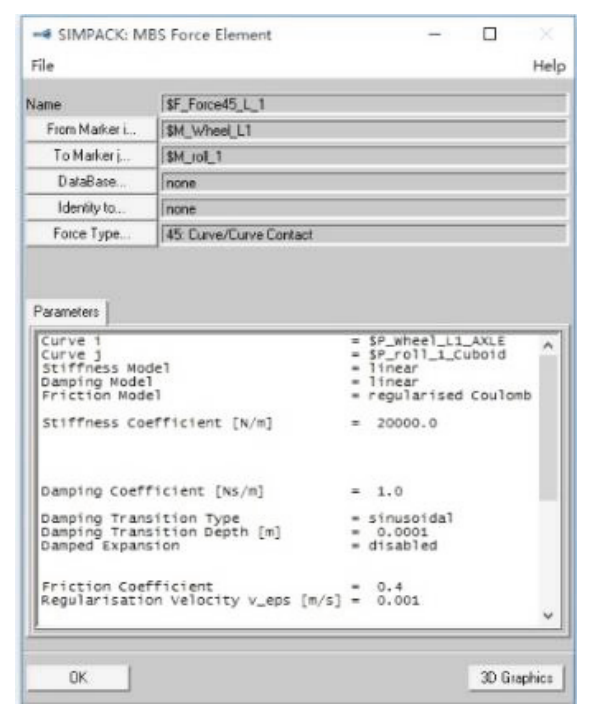

Figure 4: Parameters of force element number 45.

force and creepage is calculated using the FASTSIM $[14,15]$ algorithm, the simplified theory of Kalker.

The wear power of wheel $P$ reflects the wear on the wheelrail tread, which, ignoring the spin creep of the wheelset, is calculated by the following formula [16]:

$$
P=V \cdot\left(T_{x} \xi_{x}+T_{y} \xi_{y}\right) .
$$

The wear power of the whole vehicle is the algebraic sum of wear power of all eight wheels, which reflects the wheel-rail wear of the whole vehicle.

4.1. Analysis of Reset Capability on Straight Track. The wheelset negotiates a curve at a speed of $60 \mathrm{~km} / \mathrm{h}$, with wheels laterally displaced outward to the curve and against the outer track. When the wheelset passes the curved track and enters the straight track, the lateral movements of the three types of wheelsets are investigated and lateral displacement of each wheelset is calculated to determine their ability to get back on the middle position of the straight track. The curve is set with a radius of $400 \mathrm{~m}$ without superelevation.

As can be seen from Figure 6, only the FCIRW and the rigid wheelset eventually return to the middle position of the track, FCIRW 4.67 seconds later than the rigid wheelset in terms of resetting time. Once passing the curved track, longitudinal creep force of IRW is immediately reduced to zero, indicating a poor resetting capability. As for the rigid wheelset, the longitudinal creep force is symmetrical on the entire track, with the maximum amplitude of $16.76 \mathrm{kN}$, longitudinal creep moment of $11.0 \mathrm{kN} \cdot \mathrm{m}$ on the circular curve. For FCIRW, longitudinal creep moment is $375.9 \mathrm{Nm}$ on the circular curve; while passing the curve, longitudinal creep force is symmetrical, with the maximum amplitude of $0.30 \mathrm{kN}$. Comparing the two maximum amplitudes, it can be seen that the difference in longitudinal creep force required for wheelset resetting is as large as 56 times, which indicates that the longitudinal creep force required 


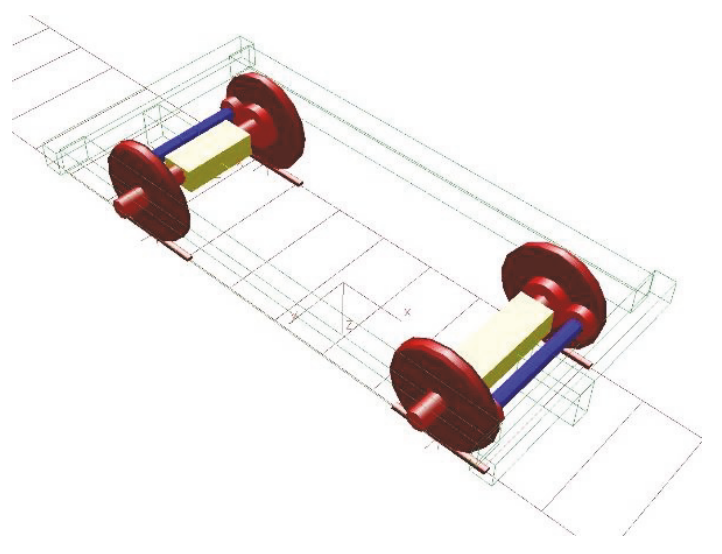

(a)

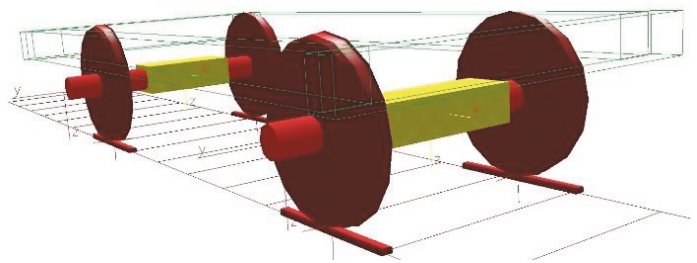

(b)

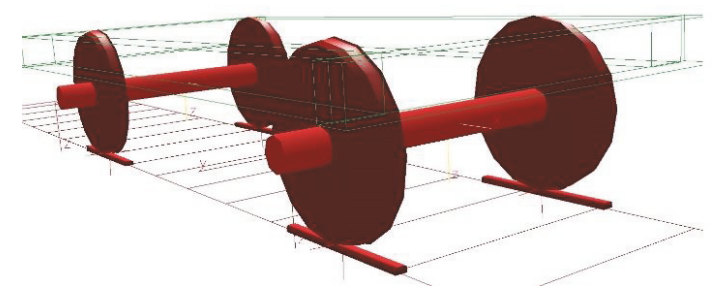

(c)

FIgURE 5: Structure of bogies: (a) dynamics model of FCIRW-bogie, (b) dynamics model of IRW-bogie, and (c) dynamics model of bogie with rigid wheelset.

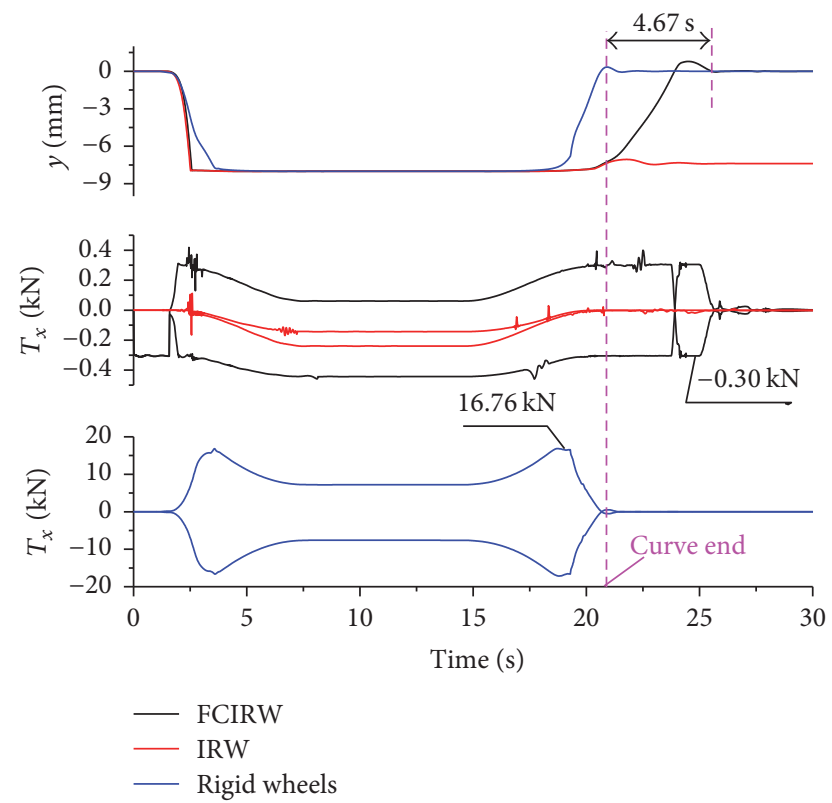

FIGURE 6: Relationship between longitudinal creep force and lateral displacement of wheelsets.

for wheelset resetting is not necessarily large and $300 \mathrm{~N}$ is sufficient in this case.

4.2. Comparison of Critical Speed of the Whole Vehicle. The simulation process is as follows: the vehicle passes a straight track with irregularity at a certain speed, and then it runs on a smooth straight track. The nonlinear critical speed can be determined according to the convergence of wheelset lateral displacement. The type of track excitation is chosen as trackrelated; the original and the final position of excitation are $30 \mathrm{~m}$ and $100 \mathrm{~m}$, respectively; the length of smooth track is $5 \mathrm{~m}$. Force element number 5 is used to link car body and ground. With this force element, the speed of the vehicle running at a high speed is gradually reduced and finally stops. In this process, if the wheelset lateral displacement is smaller than $0.15 \mathrm{~mm}$, it is considered to be convergent, and the maximum speed corresponding to that lateral displacement is the nonlinear critical speed.

In Figure 7, the curve shows the lateral displacement of the first wheelset of a rigid-wheelset bogie; the critical speed of the vehicle of rigid-wheelset bogie is $316 \mathrm{~km} / \mathrm{h}$. In Figure 8 , the curve shows the lateral displacement of the first wheelset of a FCIRW bogie; the critical speed is $522 \mathrm{~km} / \mathrm{h}$.

The critical speed of FCIRW is $206 \mathrm{~km} / \mathrm{h}$ larger than that of rigid wheelset. The amplitude of vibration increases sharply after the rigid wheelset becoming instable; the amplitude of vibration increases slowly after FCIRW becoming instable.

\subsection{Comparison of Guiding Performances on Large-Radius} Curved Track. To investigate the guiding capability of the three bogies, parameters of curve conditions are set and shown in Table 2. For clear comparative analysis, no track irregularity is applied and comparison is made on the guiding performance of the first and second wheelsets of the front bogies on curved track under idle running condition. The 
TABLE 2: Curving conditions.

\begin{tabular}{lccccc}
\hline $\begin{array}{l}V \\
(\mathrm{~km} / \mathrm{h})\end{array}$ & $\begin{array}{c}\text { Curve radius } \\
(\mathrm{m})\end{array}$ & $\begin{array}{c}\text { Length of circular arc } \\
(\mathrm{m})\end{array}$ & $\begin{array}{c}\text { Superelevation } \\
(\mathrm{mm})\end{array}$ & $\begin{array}{c}\text { Deficient superelevation } \\
(\mathrm{mm})\end{array}$ & $\begin{array}{c}\text { Length of transition track } \\
(\mathrm{m})\end{array}$ \\
\hline 290 & 3000 & 200 & 270 & 60 & 300 \\
\hline
\end{tabular}

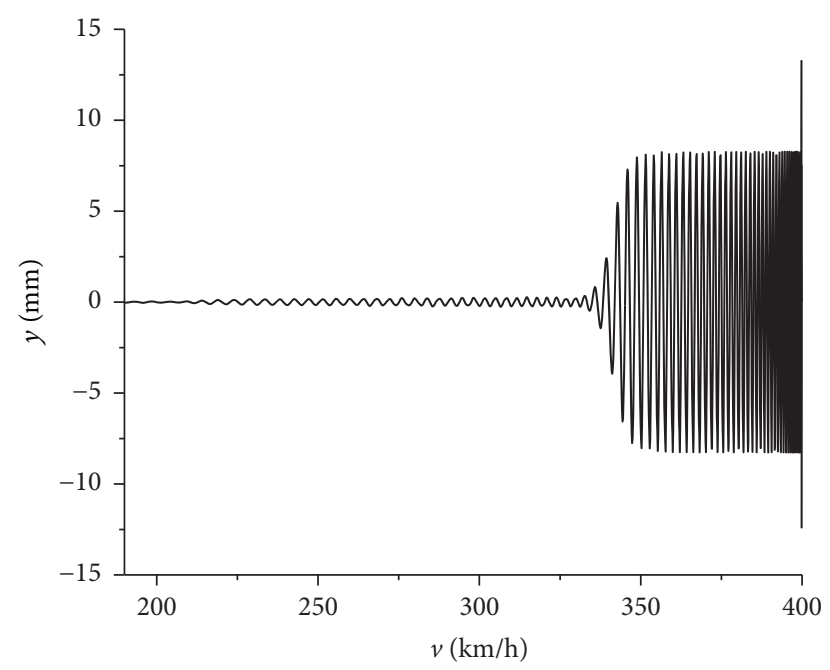

FIGURE 7: Lateral displacement of the first wheelset on bogie with rigid wheelset.

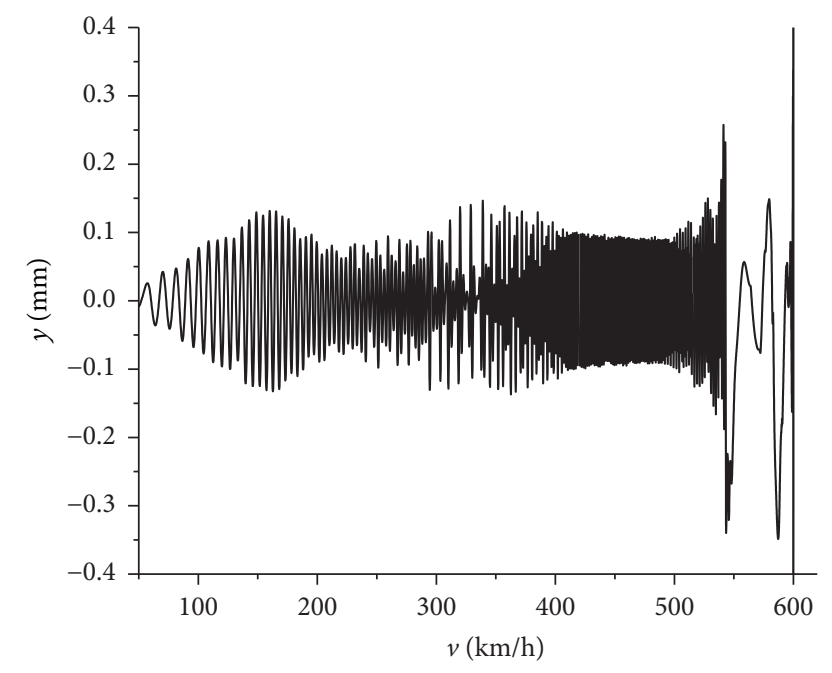

FIGURE 8: Lateral displacement of the first wheelset of FCIRW bogie.

cant deficiency of high speed is set according to the ride comfort. To be specific, cant deficiency values of 40,60 , and 90 correspond, respectively, to ride comfort grades of excellent, good, and ordinary. In this case, the cant deficiency is $60 \mathrm{~mm}$.

As is shown in Figure 9, longitudinal creep force of FCIRW is basically symmetrical on the large-radius curve, and longitudinal creep moment on the circular curve is $443.1 \mathrm{~N} \cdot \mathrm{m}$.

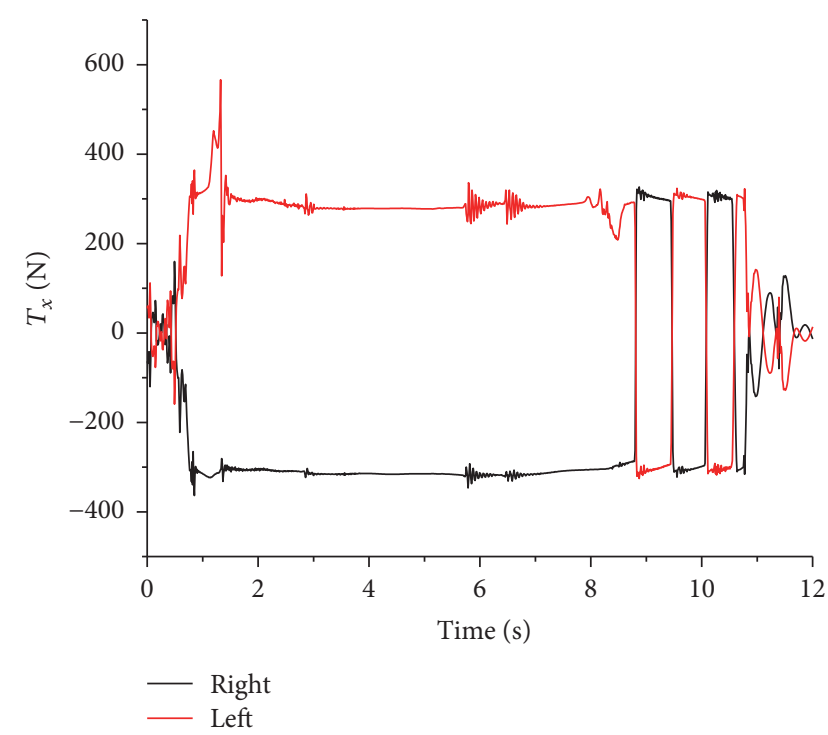

FIGURE 9: Longitudinal creep force of the first wheelset of FCIRWbogie.

When the vehicle negotiates the large-radius curve at high speed, angle of attack of the first wheelset of FCIRW is smaller than that of the IRW on the circular curve, as shown in Figure 10, due to the auxiliary effect of the longitudinal creep force of rigid wheelsets. On the circular curve, longitudinal creep force acting on the first FCIRW cannot provide enough guiding moment due to the small value, so its angle of attack is almost the same as that of the IRW; angle of attack of the second FCIRW is adjusted near the zero value and better than that of the second rigid wheelsets. After negotiating the curve, FCIRW automatically returns to the middle position of the track under the action of the longitudinal creep force, its resetting time 1.8 seconds later than that of the rigid wheelsets. Due to the poor guiding capacity, just as IRW, the first wheelset of the FCIRW-bogie completely relies on the guiding of the flange when negotiating the curve while the second wheelset only depends on it when entering and leaving the curve.

The resetting time of FCIRW is close to that of rigid wheelsets, yet IRW does not have automatic resetting capability.

As shown in Figure 11, despite the dependence on flange guiding, the lateral force of the second wheelset of FCIRWbogie on the large-radius curve is only $1 / 3$ of that of the rigid wheelset, while the lateral force of the first wheelset is only 1.7 times larger. 

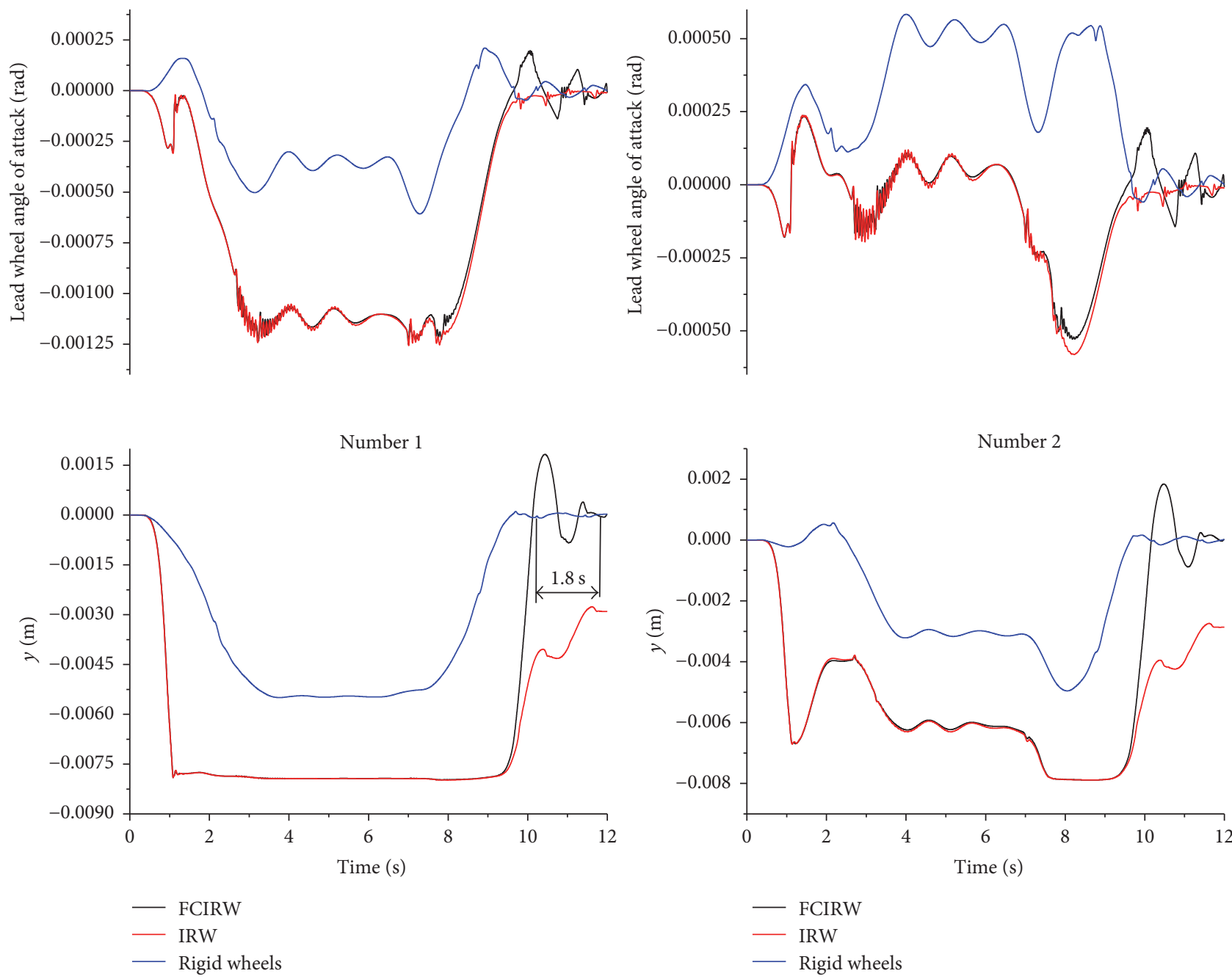

First wheelset

Second wheelset

FIGURE 10: Angle of attack and lateral displacement of the first and second wheelsets.
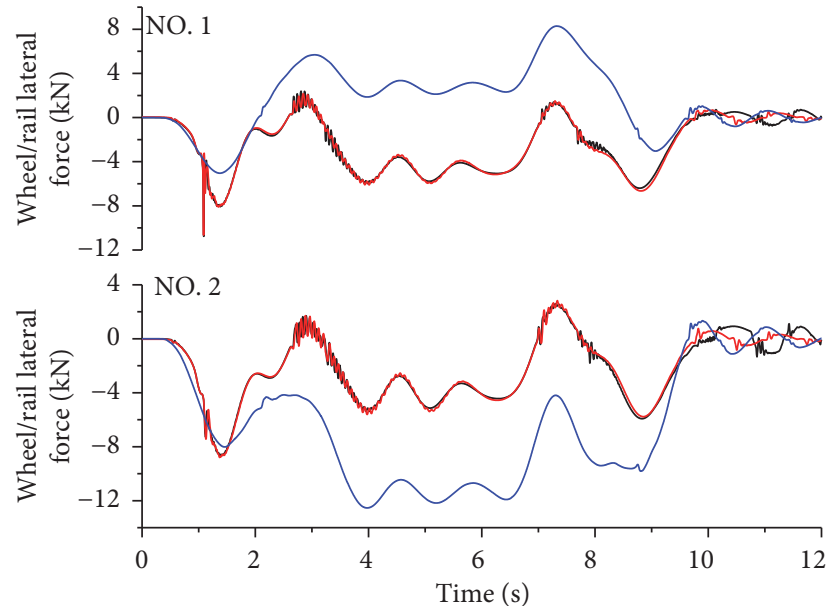

- FCIRW-bogie

— IRW-bogie

— Rigid wheels-bogie

FIGURE 11: Wheel/rail lateral force.
As shown in Figure 12, the whole vehicle wear power of vehicle with FCIRW-bogie is the same as that with IRWbogie, both of which are about $2 / 3$ of the rigid axle level.

\section{Conclusion}

The dynamics models of three vehicles are established, and their high-speed performances are studied. The following results are obtained by comparative analysis.

(1) FCIRW has longitudinal creep force which is about 56 times different from that of the rigid wheelset. Qualitative studies have shown that longitudinal creep forces do not need to be too large for the wheelset to be automatically reset on a straight track, whereas small longitudinal creep forces on the curve are not sufficient to provide guidance. Thanks to longitudinal creep force, FCIRW has the capability of resetting on a straight track as the rigid wheelset, which solves the problem of IRW running against one side of the track. 


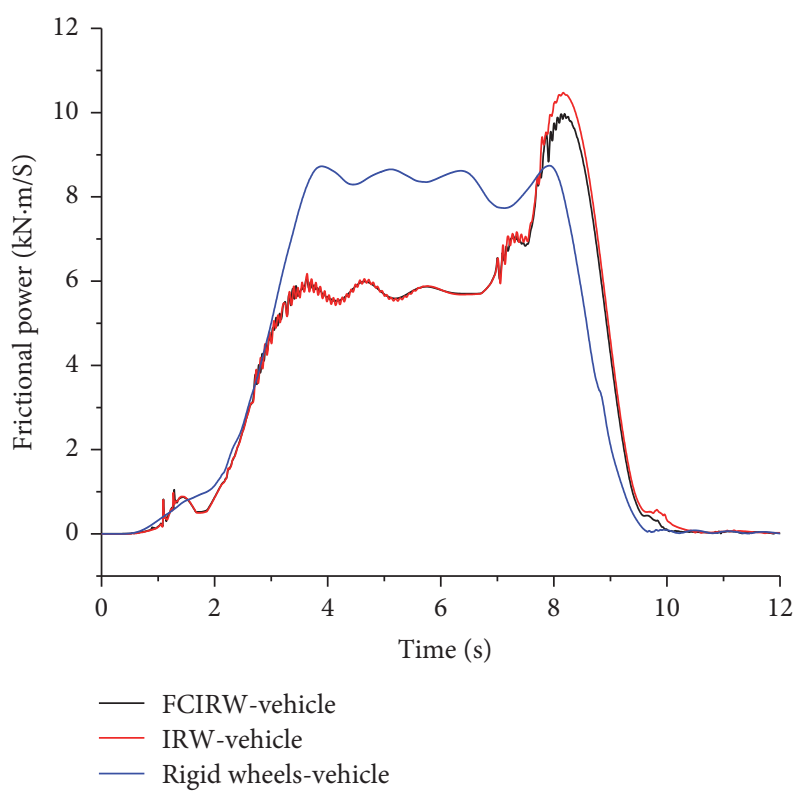

FIGURE 12: Comparison of wear power of the whole vehicle.

(2) FCIRW inherits the merits of IRW such as high critical speed and ability to achieve low floor. The critical speed of FCIRW-bogie is significantly higher than bogie with rigid wheelset.

(3) Although angle of attack of the first wheels of FCIRWbogie is larger than that of rigid wheelset, the magnitude for angle of attack on large-radius curve actually is very small. For high-speed train, large-radius curving performance is not a major problem. The overall performance of FCIRW-bogie is slightly better than that of bogie with rigid wheelset and the whole vehicle wear power of the former is lower than that of the latter.

\section{Conflicts of Interest}

The authors declared no potential conflicts of interest with respect to the research, authorship, and/or publication of this article.

\section{Acknowledgments}

The authors are grateful for the grants provided by Traction Power State Key Laboratory Exploration Project (2016TPLT06) and the National Natural Science Foundation of China (Grant no. 51575458).

\section{References}

[1] R. Goodall and H. Li, "Solid axle and independently-rotating railway wheelsets - a control engineering assessment of stability," Vehicle System Dynamics, vol. 33, no. 1, pp. 57-67, 2000.

[2] J. Winter, "Novel rail vehicle concepts for a high speed train: the next generation train," in Proceedings of the International Conference on Railway Technology: Research, Development and Maintenance, 2012.
[3] P. Courtois, "Different lateral dynamic operating conditions of a railway vehicle fitted with independently rotating wheels," Vehicle System Dynamics, vol. 23, no. 1, pp. 246-261, 1994.

[4] A. Yerpes, R. Manzano, P. Conejo, and E. Jimenez, "Talgo Hybrid Train: Maximum interoperability in propulsion system," in Proceedings of the 2012 Electrical Systems for Aircraft, Railway and Ship Propulsion, ESARS 2012, October 2012.

[5] M.-C. Xu and J. Zeng, "Guiding mechanism of longitudinal coupling bogie with independently rotating wheels," Journal of Traffic and Transportation Engineering, vol. 11, no. 1, pp. 43-50, 2011.

[6] H. Hondius, "Suppliers consolidate, but car variety keeps growing," Railway Gazette International, vol. 157, pp. 16-24, 2001.

[7] M. Ying, L. Diao, W. Lei, Z. Li, W. Lin, and Z. Liu, "Network system research and design for $100 \%$ low floor light rail vehicle," in Proceedings of the 2008 IEEE Vehicle Power and Propulsion Conference, VPPC 2008, pp. 1-5, September 2008.

[8] R. Leo, "Creep-controlled wheelsets for high speed servicetheory and test results," in Proceedings of the 8th International Wheelset Congress, vol. 1, pp. 1-16, Madrid, spain, 1985.

[9] R. Goodall, "Active railway suspensions: Implementation status and technological trends," Vehicle System Dynamics, vol. 28, no. 2-3, pp. 87-117, 1997.

[10] G. Bureika, L. P. Lingaitis, and Š. Mikaliūnas, "Investigation of dynamic models of independently rotating wheels of wagons," Transport, vol. 19, no. 1, pp. 28-31, 2004.

[11] J. J. Kalker, Three-Dimensional Elastic Bodies in Rolling Contact, Springer Science \& Business Media, 2013.

[12] F. Gan, H. Dai, H. Gao, and M. Chi, "Wheel-rail wear progression of high speed train with type S1002CN wheel treads," Wear, vol. 328-329, pp. 569-581, 2015.

[13] J. A. Elkins and B. M. Eickhoff, "Advances in nonlinear wheel/rail force prediction methods and their validation," Journal of Dynamic Systems, Measurement, and Control, vol. 104, no. 2, pp. 133-142, 1982.

[14] M. Sh. Sichani, R. Enblom, and M. Berg, "A fast wheel-rail contact model for application to damage analysis in vehicle dynamics simulation," Wear, vol. 366-367, pp. 123-130, 2016.

[15] E. A. H. Vollebregt and P. Wilders, "FASTSIM2: A second-order accurate frictional rolling contact algorithm," Computational Mechanics, vol. 47, no. 1, pp. 105-116, 2011.

[16] S. Yan, W. Ma, Z. Wu, and L. Zong, "Comparison of curving performance among bogies of different types," Journal of the Balkan Tribological Association, vol. 22, no. 2, pp. 1175-1183, 2016. 


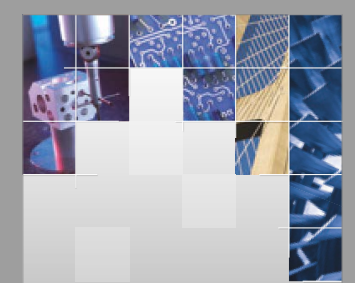

\section{Enfincering}
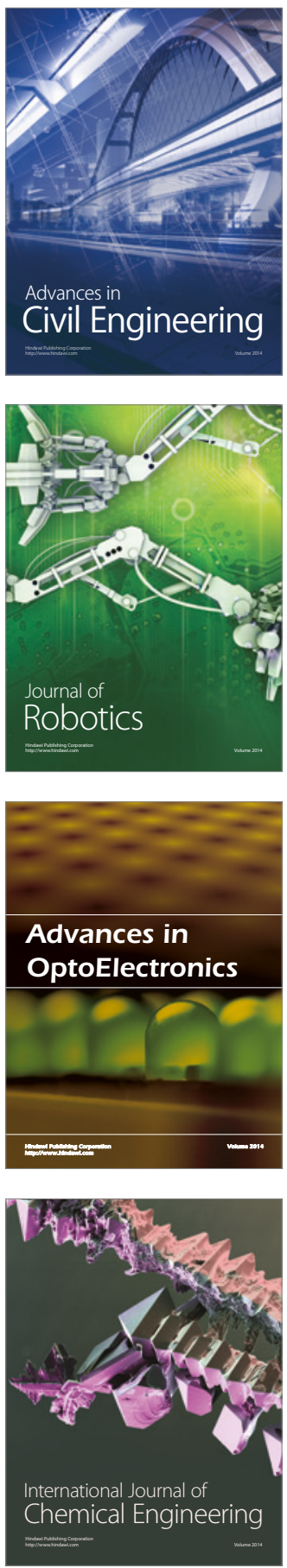

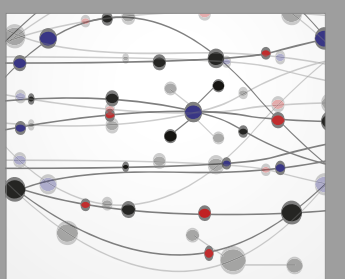

The Scientific World Journal

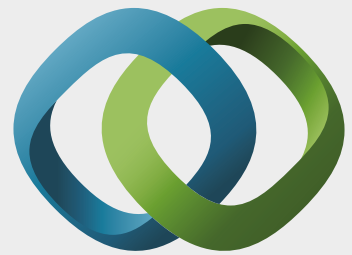

\section{Hindawi}

Submit your manuscripts at

https://www.hindawi.com
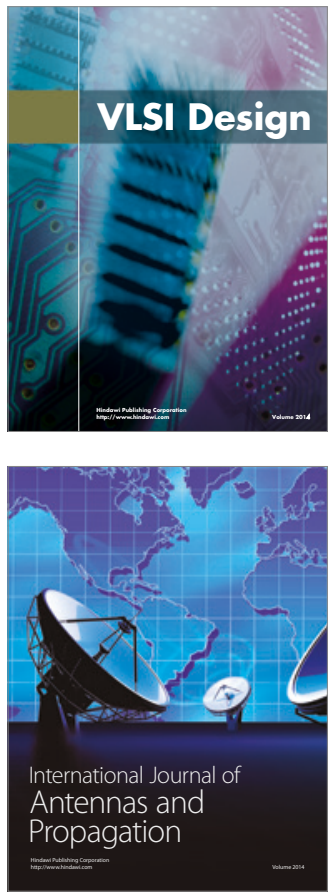

\section{Rotating}

Machinery
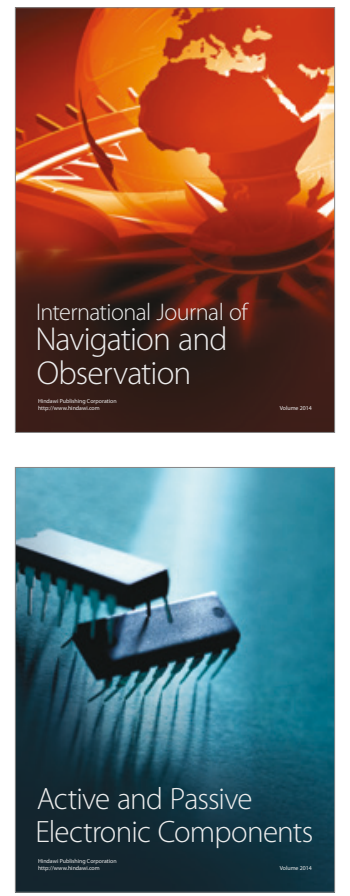
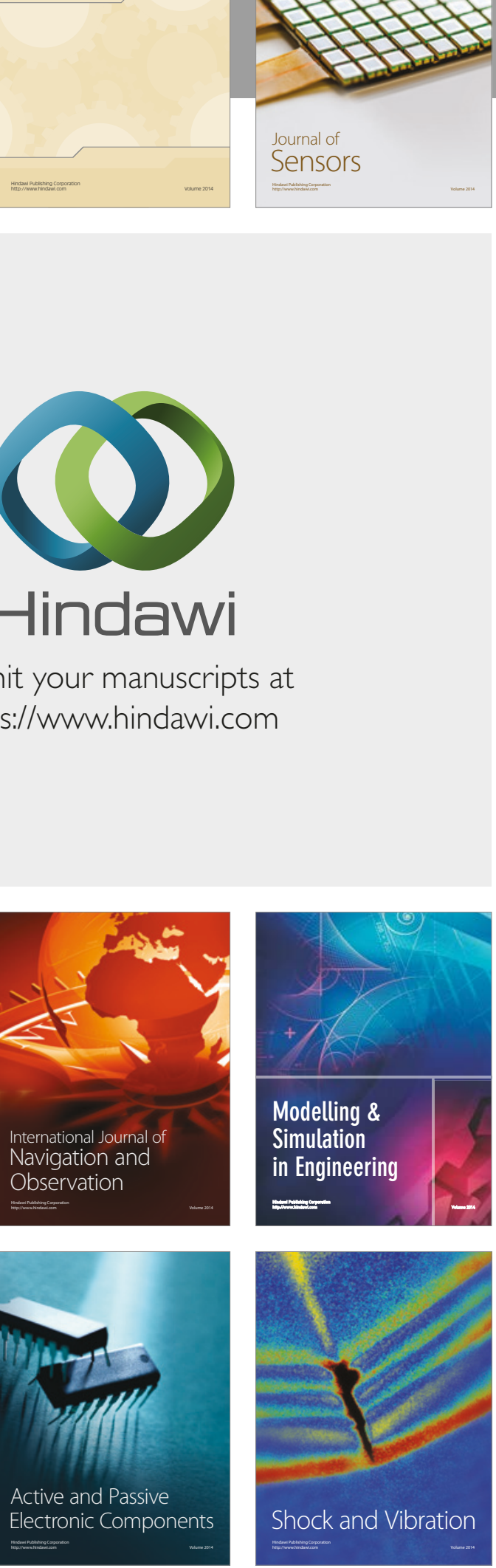
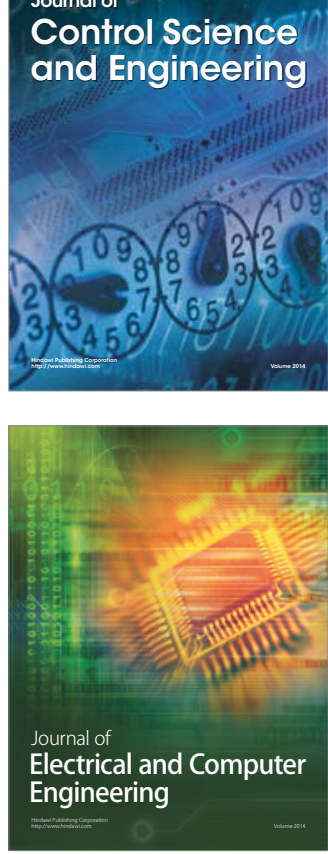

Distributed

Journal of

Control Science

and Engineering
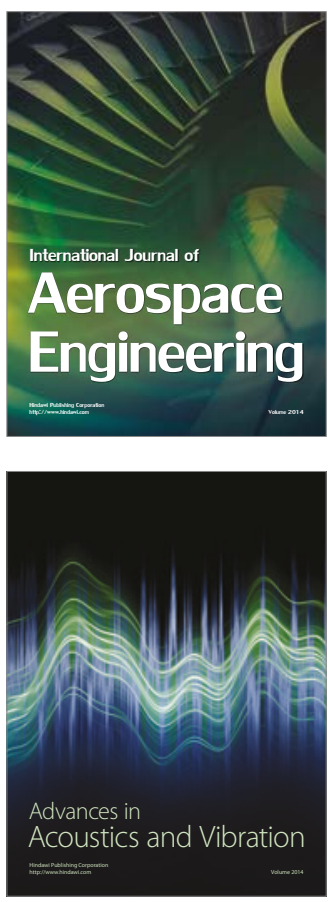

Sensor Networks 